\title{
Prevalence of Gall Stones in Liver Cirrhosis
}

\author{
Sudhamshu K.C., ${ }^{1,2}$ Dilip Sharma, ${ }^{1}$ Sandip Khadka, ${ }^{1}$ Niyanta Karki, ${ }^{1}$ Bikash Jaishi, ${ }^{1}$ Kiran Regmi, ${ }^{1}$ Dipendra \\ Khadka' \\ 'Liver Unit, National Academy of Medical Sciences, Bir Hospital, Kathmandu, Nepal, ${ }^{2}$ Norvic International Hospital, \\ Kathmandu, Nepal.
}

\section{ABSTRACT}

Introduction: Increased incidence and prevalence of gallstones in liver cirrhosis has already been reported by many studies. This study aimed to investigate the prevalence of gallstone disease in Nepali patients with liver cirrhosis and to identify risk factors for gallstone formation.

Method: Consecutive patients of liver cirrhosis presenting to liver clinic from January, 2010 to December, 2012 were evaluated for GS by ultrasonography at their first visit. Liver cirrhosis was diagnosed on the basis of clinical features, laboratory parameters, ultrasonography, and/or histopathology.

Result: Two hundred and twenty four LC patients were studied. Male to female ratio was 2.3:1. Alcohol was the major etiological factor for LC followed by hepatitis B, alone or in conjunction with alcohol. Seventy-four patients (33\%) were found to have GS. Incidence of GS was more in advance stage of cirrhosis. There was no significant correlation between formation of GS and etiology of LC, except for the HCV related liver cirrhosis, in which it was present in 39\% of the patients. More the advance disease,more was the incidence as $57 \%$ of Child-C patients had GS. Portal vein diameter was also associated with GS formation. When portal vein diameter was more than $13 \mathrm{~mm}$, there was more GS formation.

Conclusions: One third of the patients of LC showed GS at the presentation. Patients with HCV related cirrhosis are more prone to develop GS than other. Severity of the disease and portal vein diameter was found to be associated with GS formation.

Keywords: gallstones; liver cirrhosis; ultrasonography.

\section{INTRODUCTION}

The prevalence of gallstones (GS) has been reported from $29-59 \%$ in liver cirrhosis (LC) patients in different studies. $^{1-6}$ The yearly incidence of cholelithiasis in patients with cirrhosis ranges from $2 \%$ to $4.7 \%$ in prospective, ultrasound studies. ${ }^{6,7,8}$ When indicated treatment is necessary. However, the morbidity rate is higher, if carried out in advance cirrhotic patients, if compared to non-cirrhotic patients. Majority of the patients are asymptomatic and stones are found as incidental findings during radiological investigations while evaluating the liver disease. Real-time ultrasonography is preferred imaging technique in evaluating the gallbladder and its pathology as it is easily available, cost effective, non-invasive and easily

Correspondence: Dr. Sudhamshu K.C., Liver Unit, National Academy of Medical Sciences, Bir Hospital, Kathmandu, Nepal. E-mail: sudhamshu.liver@gmail.com , Phone: +977-9851081599. 
reproducible. Sensitivity of USG in detecting gallstones is $95 \% .^{9}$

This study was done to find out the prevalence of gallstones in liver cirrhosis patient of different etiologies.

\section{METHODS}

This study was carried from January, 2010 to December, 2012 in Liver unit of Bir hospital and Norvic International Hospital in Kathmandu valley. Consecutive patients of liver cirrhosis attending liver clinic for ultrasound abdomen were enrolled in this prospectively designed observational study. Liver cirrhosis was diagnosed on the basis of clinical findings, evidence of portal hypertension (clinical, radiological and endoscopic), radiological investigations (ultrasonography and/or CT scan or MRI) and/or histopathological examination. All patients underwent ultrasound abdominal scanning (by Logiq 300 or Medison with a transducer of 3.5or $5-\mathrm{MHz}$ ) after overnight fasting. The patients with definite strong echogenic focus in the gall bladder lumen/neck with distal acoustic shadow or the patients with absent gall bladder due to previous history of cholecystectomy for gall stones were taken as having gallstones. The number and size of gallstones and the gallbladder wall thickness were noted. Those having sludge in the gall bladder were excluded from the study. The measurement of spleen was done as per techniques used by Matsutani et al. ${ }^{10}$ The patients were graded according to Child-Pugh scoring system. ${ }^{11}$ The risk factors considered for the assessment were age, sex, bilirubin, hemoglobin, platelets count, Child-Pugh grading, spleen size and portal vein diameter. Whenever platelet count was below $50000 / \mathrm{mm}^{3}$, it was repeated and done manually.

To compare the prevalence of GS in non-cirrhotic patients and to compare between two groups, patients with liver disease presenting for the first time without prior history of liver disease were randomly selected and USG was performed.

Informed consent was obtained from every patient before enrolment into the study and the study was approved by Institutional Review board. SPSS ver. 20 was used for statistical analysis.

\section{RESULTS}

A total of 224 patients were enrolled in the study. The demographic profile of the patients is given in table 1. There was male preponderance with a $M: F$ ratio of 2.3:1. The youngest patient presenting with cirrhosis with gallstone was 35 years. Etiology of LC was chronic hepatitis $C$ plus alcohol. The etiologies of $\mathrm{LC}$ are given in table 2. Alcohol was the predominant cause of LC. Based on Child-Pugh scoring, 58(26\%), $119(53 \%)$ and $47(21 \%)$ patients were in A, B and C groups respectively.

\begin{tabular}{|ccc|}
\hline Table 1. Demographic profile of the patients. \\
\hline Age (years) & Male (\%) & Female (\%) \\
$30-40$ & 6 & 1 \\
$41-50$ & 54 & 27 \\
$51-60$ & 50 & 21 \\
$61-70$ & 33 & 12 \\
$>71$ & 14 & 6 \\
& $157(70)$ & $67(30)$ \\
\hline
\end{tabular}

\begin{tabular}{|lc|}
\hline Table 2. Etiology of liver cirrhosis. \\
\hline Etiology & No. (\%) \\
Alcohol & $135(60.2)$ \\
Alcohol + hepatitis B & $26(11.6)$ \\
Alcohol + hepatitis C & $16(7.1)$ \\
Hepatitis B & $12(5.4)$ \\
Hepatitis C & $12(5.4)$ \\
Budd-Chiari syndrome & $8(3.6)$ \\
Wilson's disease & $5(2.2)$ \\
Autoimmune hepatitis & $4(1.8)$ \\
Cryptogenic & $4(1.8)$ \\
Primary biliary cirrhosis & $2(0.9)$ \\
\hline
\end{tabular}

Table 3. Age distribution of patient with gallstones.

\begin{tabular}{|rcc|}
\hline Age (years) & Male & Female \\
$30-40$ & 1 & 0 \\
$41-50$ & $12^{*}$ & $13^{*}$ \\
$51-60$ & 16 & $10^{*}$ \\
$61-70$ & 10 & 6 \\
$>71$ & 3 & 3 \\
& 42 & 32 \\
\hline
\end{tabular}

* Patients with prior cholecystectomy included

\begin{tabular}{|c|c|c|c|c|}
\hline & & $\begin{array}{l}\text { Child- } \\
\text { Pugh A }\end{array}$ & $\begin{array}{l}\text { Child- } \\
\text { Pugh B }\end{array}$ & $\begin{array}{l}\text { Child- } \\
\text { Pugh C }\end{array}$ \\
\hline \multirow{2}{*}{$\begin{array}{l}\text { Total } \\
\text { patients }\end{array}$} & Male & 39 & 92 & 26 \\
\hline & Female & 19 & 27 & 21 \\
\hline \multirow{2}{*}{$\begin{array}{l}\text { Patients } \\
\text { with } \\
\text { gallstone }\end{array}$} & Male & $9(23 \%)$ & $\begin{array}{l}22 \\
(24 \%)\end{array}$ & $\begin{array}{l}11 \\
(42 \%)\end{array}$ \\
\hline & Female & $6(32 \%)$ & $\begin{array}{l}10 \\
(37 \%)\end{array}$ & $\begin{array}{l}16 \\
(76 \%)\end{array}$ \\
\hline
\end{tabular}


K.C. et al. Prevalence of Gall Stones in Liver Cirrhosis

\begin{tabular}{|c|c|c|c|c|}
\hline \multirow{2}{*}{ Characteristics } & \multicolumn{2}{|c|}{ Cholelithiasis } & Odd'sratio & \multirow{2}{*}{$\mathrm{p}$ value } \\
\hline & Present & Absent & $95 \% \mathrm{Cl}$ & \\
\hline Age & $56.67 \pm 9.63$ & $55.67 \pm 10.21$ & & $0.48 *$ \\
\hline Sex (male/female) & $42 / 32$ & $115 / 35$ & $2.50(1.38-4.50)$ & $0.003 * *$ \\
\hline \multicolumn{5}{|l|}{ Disease severity } \\
\hline Child A & $15(20.27)$ & $25(16.66)$ & $0.78(0.38-1.60)$ & $0.48 * *$ \\
\hline Child B & $32(43.24)$ & $105(70.00)$ & $3.06(1.71-5.45)$ & $0.00 *$ \\
\hline Child C & $27(36.48)$ & $20(13.33)$ & $3.73(1.91-7.27)$ & $0.00 * *$ \\
\hline Dilated portal vein $(\geq 13 \mathrm{~mm})$ & $38(51.35)$ & $105(70.00)$ & $0.45(0.25-0.80)$ & $0.007 * *$ \\
\hline Portal vein diameter (mm) & $13.35 \pm 2.39$ & $11.81 \pm 2.52$ & & $0.00 *$ \\
\hline High spleenic index $\left(\geq 20 \mathrm{~cm}^{2}\right)$ & $26(16.21)$ & $45(30.00)$ & $0.79(0.43-1.42)$ & $0.43 * *$ \\
\hline Spleenic index $\left(\mathrm{cm}^{2}\right)$ & $23.56 \pm 4.76$ & $25.95 \pm 8.52$ & & $0.02 *$ \\
\hline High Bilirubin & $55(74.32)$ & $96(64.00)$ & $2.86(1.19-6.82)$ & $0.019 * *$ \\
\hline Bilirubin (mg \%) & $1.43 \pm 0.49$ & $2.20 \pm 1.48$ & & $0.06 *$ \\
\hline Low platelets (/mm3) & $49(66.21)$ & $86(57.33)$ & $1.45(0.81-2.60)$ & $0.20 * *$ \\
\hline Platelets $\left(/ \mathrm{mm}^{3}\right)$ & $137517 \pm 103924$ & $145345 \pm 71885$ & & $0.51 *$ \\
\hline Low Hemoglobin ( $\leq 12 \mathrm{gm} \%$ ) & $62(83.78)$ & $120(80.00)$ & $1.29(0.61-2.69)$ & $0.49 * *$ \\
\hline Hemoglobin (gm\%), & $10.17 \pm 1.86$ & $10.09 \pm 1.98$ & & $0.75 *$ \\
\hline
\end{tabular}

Value shown as mean \pm SD or $\mathrm{n}(\%),{ }^{*}$ Student's t-test, ${ }^{*}$ Univariate logistic regression analysis

\begin{tabular}{|lcc|}
\hline $\begin{array}{l}\text { Table 6. Multivariate conditional logistic regression } \\
\text { analysis of risk factors of cholelithiasis in cirrhosis } \\
\text { patients. }\end{array}$ \\
\hline \multicolumn{3}{|c}{ Odds ratio } \\
Characteristics & $(95 \% \mathrm{Cl})$ & P-value* \\
Sex & $2.007(1.06-3.79)$ & 0.032 \\
Child C & $0.210(0.10-0.44)$ & 0.000 \\
$\begin{array}{lcc}\text { Dilated portal } \\
\text { vein }(\geq 13 \mathrm{~mm})\end{array}$ & $0.320(0.17-0.62)$ & 0.001 \\
\hline
\end{tabular}

Only variables with $\mathrm{P}<0.1$ in univariate logistic regression analysis were considered for multivariate conditional logistic regression analysis

Seventy-four patients (33\%) were found to have gall stones. The $M: F$ ratio of patients with gall stone was 1.3:1. It was more evident in the 41-60 years age group. Eight patients had cholecystectomy in the past. Wedge biopsy taken per-operatively that lead to the diagnosis of liver cirrhosis. Sixteen patients with sludge in the gall bladder were seen and were not included in the stone group. Follow up for the formation of gall stone was out of scope of this study. However, it is one of the risk factor for the formation of GS. Out of 74, 51 patients had multiple small stones. Fifteen had single stone and remaining 8 had $2-3$ stones. Maximum size of the stone observed was $5.4 \mathrm{~cm}$.

Twelve patients were symptomatic at the time of presentation. USG revealed thickened, edematous gall bladder with partially collapsed lumen containing stones.
Eight patients having Child-Pugh A class underwent laparaoscopic cholecystectomy while remaining 4 patients were treated conservatively. Majority (6/8) showed black stones and brown stone was seen in 2 patients. Two patients went to hepatic encephalopathy after the surgery. However, encephalopathy was reverted with conservative therapy.

Incidence of GS was compared in cirrhotic patients of alcoholic and non-alcoholic etiology (data not shown). There was no statistical significant between two groups. Out of $28 \mathrm{HCV}$ related cirrhotic patients, 11 patients (39\%) had gallstones and one had prior cholecystectomy.

During same study period randomly selected 568 patients of various liver diseases (non-cirrhotic) underwent abdominal ultrasonography. They were predominantly patients suffering from acute viral hepatitis. 40 patients (7\%) were found to have gallstones. Only 5 patients were symptomatic at the time of presentation. 60 patients were having sludge in the gall bladder.

Table 5 shows the distribution of studied variables among liver cirrhosis patients with presence or absence of gall stone. Only variables with $\mathrm{P}<0.1$ in univariate logistic regression analysis were considered for multivariate conditional logistic regression analysis.

Severe the disease assessed by Child Pugh score system, more prevalent was the stone formation. So, GS was prevalent in Child-C patients $(p>001)$. Out 
of 47 patients with Child C status, 27(57\%) had GS. Similarly portal vein diameter was also associated with GS formation $(p>0001)$. When portal vein diameter was more than $13 \mathrm{~mm}$, there was more GS formation. Fifty one percent of the patients with GS were found to have GS.

\section{DISCUSSION}

In this study thirty-three percent of the cirrhotic patients were found to have gallstones. This finding is comparable with previous study. ${ }^{6}$ The incidence was much higher compared to the non-cirrhotic patients (7\%) seen during same period of study. Etiology of liver cirrhosis was alcohol in 60 percent of the patient. Nonetheless, there was no statistically significant difference between prevalence of GS in alcohol and non-alcohol etiology.

However, in this study it was found that the HCV infected patient showed higher prevalence of GS compared to non infected person. It is plausible that the HCV can successfully infect gallbladder epithelial cells that may potentially impair or alter gallbladder mucosal function and contribute to the development of GS. Current finding is comparable to previous studies. ${ }^{12,13}$

It is now established that the liver cirrhosis is an important risk factor for the development of GS, and that the majority of GS in cirrhotic patients are pigment stones. Several factors may be responsible for formation of GS in cirrhotic patients. Reduced hepatic synthesis and transport of bile salts, ${ }^{14}$ impaired gallbladder motility, ${ }^{15,16}$ and chronic haemolysis following hypersplenism. ${ }^{4}$ There is increased prevalence of GS in advanced stage of cirrhosis. ${ }^{2,3,7}$ Similar result was obtained in this study. In present study, it was found that compared to Child A and B group GS was more prevalent in Child $C$ group (table 4). Formation of gall stone was not associated with large spleen (Splenic index more than $20 \mathrm{~cm}^{2}$ ). As there is increase incidence of black stone in cirrhotic patients, before study, it was assumed that the sequestration of blood in the enlarged spleen can have more hemolysis compared to smaller spleen. On line with this finding, there was no correlation of platelets counts and haemoglobin level with increase incidence of GS.

It was found in some studies that the frequency of GS increases with advancing age. ${ }^{6,17,18}$ But in this study there was no such relation between age and GS was found. However, there is limited number of elderly patients in this study. The limited numbers of elderly patients can be attributed to early appearance of LC in our country. The youngest patient diagnosed was 35 years only. Since the survival decreases with advance disease, this may be the reason for less numbers of elderly patients. There have been variable reports regarding relation between GS and female sex. Some studies reported that there is similar incidence in male and female, ${ }^{2,6}$ while one study reported increase incidence in female population. ${ }^{3}$ This study showed that female sex was one of the factors for increased GS formation. Same factors that play role in non-cirrhotic patients may be responsible in LC patients. Similar to a previous study, we found correlation between portal vein diameter and GS formation. ${ }^{18}$

Gall bladder hypomotility is said to be a contributing factor in GS formation in LC patients. ${ }^{19-21}$ However, no attempt was made to study this factor in this study. Similarly autonomic dysfunction in LC patients, which was found to be associated with increased GS formation, ${ }^{22}$ was also not studied in this study. Future study may be directed towards making out the correlations between GS formation gall bladder motility and autonomic dysfunction. Finucci $G$ et al found no close relation between any factors and GS formation. ${ }^{23}$ They later concluded that LC itself is a lithogenic condition. However, the limitation of the study was very small number of subjects.

\section{CONCLUSION}

Prevalence of gall stone was $33 \%$ in cirrhotic patients in Nepali patients, comparable to other studies. LC due to $\mathrm{HCV}$ was found to have higher rate of GS formation. Female cirrhotic patients had more GS compared to male patients. Portal vein diameter and severe disease (Child C) were found to be associated with increased GS formation.

\section{REFERENCES}

1. Bouchier IAD. Postmortem study of the frequency of gallstones in patients with cirrhosis of the liver. Gut 1969;10:705-710.

2. Acalovschi M, Badea R, Dumitrascu D, Varga C. Prevalence of gallstones in liver cirrhosis: A sonographic survey. Am J Gastroenterol 1988; 83:954 -956.
3. Fornari F, Civardi G, Buscarini E, Cavanna L, Imberti D, Rossi $\mathrm{S}$ et al. Cirrhosis of the liver. A risk factor for development of cholelithiasis in males. Dig Dis Sci 1990;35:1403-1408.

4. Iber FL, Caruso G, Polepalle C, Kuchipudi V, Chinoy M. Increasing prevalence of gallstones in male veterans with alcoholic cirrhosis. Am J Gastroenterol 1990;85:1593-1596. 
5. Fornari F, Imberti D, Squillante MM, Squassante L, Civardi $\mathrm{G}$, Buscarini E et al. Incidence of gallstones in a population of patients with cirrhosis. J Hepatol 1994;20:797- 801,

6. Conte D, Barisani D, Mandelli C, Bodini P, Borzio M, Pistoso $\mathrm{S}$ et al. Cholelithiasis in cirrhosis: analysis of 500 cases. Am J Gastroenterol 1991;86:1629-1632,

7. Benvegnu L, Noventa F, Chemello L, Fattovich G, Alberti A. Prevalence and incidence of cholecystolithiasis in cirrhosis and relation to the etiology of liver disease. Digestion 1997;58:293-8.

8. Del Olmo JA, Garcia F, Serra MA, Maldonado L, Rodrigo JM. Prevalence and incidence of gallstones in liver cirrhosis. Scand J Gastroenterol 1997; 32:1061-1065

9. Shea JA, Berlin JA, Escarce JJ. Revised estimates of diagnostic test sensitivity and specificity in suspected biliary tract disease. Arch Intern Med. 1994;154: 2573.

10. Matsutani S, Kimura K, Ohto M, Okuda K. Ultrasongraphy in the diagnosis of portal hypertension. In: Okuda K, Benhamou JP eds. Portal Hypertension: Clinical and physiological aspects. Tokyo: Sprnger, 1987: 197-206.

11. Pugh RN, Murray-Lyon IM, Dawson JL, Pietroni MC, Williams R. Transection of the oesophagus for bleeding oesophageal varices. Br J Surg 1973; 60: 646-649.

12. Bini EJ, McGready J. Prevalence of gallbladder disease among persons with hepatitis $C$ virus infection in the United States. Hepatology 2005; 41: 1029-1036.

13. Stroffolini T, Sagnelli E, Mele A, Cottone C, Almasio PL; Italian Hospitals' Collaborating Group. HCV infection is a risk factor for gallstone disease in liver cirrhosis: an Italian epidemiological survey.J Viral Hepat. 2007 Sep;14(9):618-23.

14. Alvaro D, Angelico M, Gandin C, Ginanni Corradini S, Capocaccia L. Physico-chemical factors predisposing to pigment gallstone formation in liver cirrhosis. J Hepatol 1990; 10: 228-234.
15. Li CP, Hwang SJ, Lee FY, Chang FY, Lin HC, Lu RH et al. Evaluation of gallbladder motility in patients with liver cirrhosis: relationship to gallstone formation. Dig Dis Sci 2000; 45:1109-1114.

16. Acalovschi M, Dumitrascu DL, Nicoara CD. Gallbladder contractility in liver cirrhosis: comparative study in patients with and without gallbladder stones. Dig Dis Sci. 2004 Jan; 49(1):17-24.

17. Castellano L, De Sio I, Silvestrino F, Marmo R, Del Vecchio Blanco C. Cholelithiasis in patients with chronic active liver disease: evaluation of risk factors. Ital J Gastroenterol. 1995;27:425-429.

18. Zhang Y, Liu D, Ma Q, Dang C, Wei W, Chen W. Factors influencing the prevalence of gall stone formation in liver cirrhosis. J Gastroenterol and Hepatol 2006: 21(9) 1455-1458.

19. Kurihara N, Ide H, Omata $T$, Yonamine S, Mashima $Y$, Tanno $\mathrm{M}$ et al. Evaluation of gallbladder emptying in patients with chronic liver disease by 99mTc-EHIDA hepatobiliary scintigraphy. Radioisotopes 1989; 38:269-274.

20. Acalovschi M, Dumitrascu DL, Csakany I. Gastric and gallbladder emptying of a mixed meal are not coordinated in liver cirrhosis - a simultaneous sonographic study. Gut 1997: 40:412-417.

21. Li CP, Hwang SJ, Lee FY, Chang FY, Lin HC, Lu RH, Chu CJ, Lee SD. Evaluation of gallbladder motility in patients with liver cirrhosis: relationship to gallstone formation. Dig Dis Sci 2000; 45:1109-1114.

22. Chawla A, Puthumana L, Thuluvath PJ. Autonomic dysfunction and cholelithisis in patients with cirrhosis. Dig Dis and Sci 46:3; 495-498, 2001.

23. Finucci G, Tirelli M, Bellon S, Zambon M, Toffolo L, Merkel $\mathrm{C}$ et al. Clinical significance of cholelithiasis in patients with decompensated cirrhosis. J Clin Gastroenterol 1990;12:538 -541 . 